\title{
Donald A.B. Lindberg M.D. - My Mentor
}

\author{
Joyce A. MITCHELL Ph.D. \\ Professor Emerita ${ }^{1}$ \\ Department of Biomedical Informatics \\ University of Utah, U.S.A.
}

\begin{abstract}
Keywords. Donald A.B. Lindberg M.D., University of Missouri-Columbia, University of Utah, U.S. National Library of Medicine, history of biomedical informatics, mentorship
\end{abstract}

\section{Introduction}

This memoir focuses on a few examples of Donald A.B. Lindberg M.D.'s influence on my career in biomedical informatics. He was always accessible to me from the point of my postdoctoral fellowship starting in 1976 until I became the Chair, Board of Regents of the National Library of Medicine (NLM) in 2009, and NLM's representative on the Council of Councils for the National Institutes of Health (NIH) from 2011-2014. I retired shortly after this and was amazed that Dr. Lindberg continued to serve NLM until 2015.

I briefly describe some of the most memorable examples in this memoir. I start at the University of Missouri - Columbia (MU), move to my sabbatical at NLM, and work at the University of Utah. Dr. Lindberg and I became close colleagues over the years, but I will always consider him my primary career mentor.

\section{The University of Missouri-Columbia (MU)}

Dr. Lindberg recruited me to be a postdoctoral fellow at the University of MissouriColumbia in 1976, and he changed my whole career. Dr. Lindberg supervised some predoctoral and postdoctoral fellowships at MU as part of a health care technology training grant program. I had just finished my Ph.D. at the University of WisconsinMadison, focusing on population genetics and a graduate minor in probability and statistics with programming skills.

Specifically, I was looking in Columbia, MO., for a postdoc or a job. I married the last year of my doctoral work, and my husband was the chair of the mathematics department at Stephens College in Columbia. He wanted to be near his children as they grew up. I agreed I would look for a job in Columbia first, then Kansas City and St. Louis.

Dr. Lindberg interviewed me for the postdoc position and said: 'you have the perfect background to be part of this new field called Medical Information Sciences.' I had never heard of it but decided that I would take a leap of faith and spend two years giving it a try.

\footnotetext{
${ }^{1}$ Corresponding author: joycemittchell0@gmail.com
} 
Those two years were a fantastic, whirlwind learning experience and different from my Ph.D. work. Dr. Lindberg would become my primary mentor for my informatics career, spanning the next thirty-five years.

In the mid-1970s, the Medical Information Sciences Program at MU revolved around a center grant from the U.S. National Center for Health Services Research (NCHSR). MU was the U.S. designated Center for Health Care Technology (HCTC). We collaborated with the MU School of Medicine, College of Engineering (industrial engineering and computer engineering), College of Nursing, College of Health Sciences, School of Journalism, and School of Information Sciences. It was a stimulating, multidisciplinary environment.

The program's goal was to identify and assess new technologies that would change health care environments. We explored online information retrieval in fields such as law with LEXIS (legal information services), as well as searching on MEDLINE. This led to explorations of controlled vocabularies such as Medical Subject Headings (MeSH) and Systematized Nomenclature of Medicine - Clinical Terms (SNOMED).

We evaluated pharmacy information systems to determine if they decreased drug interactions. We assessed radiology and pathology information systems for the timeliness of their results and their impact on providers workflow. We also evaluated workflow in clinics to search for improvements in time and efficiencies and assessed the capability of early telemedicine systems to provide services to rural populations. We developed and evaluated patient communication services.

The engineers worked to create a 'computer in a briefcase,' which was a prototype for the microcomputer industry. The rapidly emerging CT scan technology warranted a comprehensive literature review. We were, in fact, collecting the literature of health services research as it focused on technology and developing a system on a microcomputer to store and retrieve the data.

We evaluated health care software with Rutgers University (Casimir Kulikowski Ph.D.) and medical experts alongside our technology focus. This led to a dual-track of relational databases compared to hierarchical databases for storage and retrieval of patient data and expert systems to assist with diagnosing and treating patients based upon such data. We began with rheumatic diseases (Gordon Sharp M.D.), branched out into dermatology (Philip Anderson M.D.), coagulation (Montgomery Gaston M.D.), and genetics (Sandra Davenport M.D.).

The NCHSR/HCTC with related grants and projects was a rich learning environment for a postdoctoral fellow. Above and beyond the content of the specific technology projects, it was instrumental for me to learn about grant site visits. Grant visitors included NLM, the U.S. National Institutes of Health (NIH), the U.S. Center for Disease Controls and Prevention (CDC), the U.S. Department of Defense (DOD), and other U.S. federal health-related agencies. I wrote my first grant, my initial scientific papers, gave professional presentations and technical demonstrations, and learned the skills vital for success in all academic fields.

My dilemma was how to get a faculty position in the MU School of Medicine to continue to be part of the exciting field and work with Dr. Lindberg and his team. At the time in the U.S., there was only one department of Medical Informatics (this name later evolved to biomedical informatics), which was located at the University of Utah. MU's School of Medicine did not have such an entity. At the time, Dr. Lindberg was the Director of the Medical Information Sciences Group, a research group that reported to the Dean of MU's School of Medicine. But the faculty all had their primary appointments in traditional departments. 
After some deliberation, I decided to apply for another postdoctoral position in clinical medical genetics. My Ph.D. in genetics had become clinically relevant to an emerging focus in MU's Department of Child Health (traditionally called Pediatrics). I took a detour and was accepted at the University of California-San Francisco for a twoyear fellowship. I focused on clinical genetics but researched the development of a clinical information system to assist in retrieving patients with clusters of symptoms that might form new syndromes. After developing this on a University mainframe, I transferred it to a North Star microcomputer. The latter was a boon to the genetics research community and broke new ground using microcomputers in the clinical domain.

The happy ending was my acceptance of an offer of an assistant professor tenuretrack position in the Department of Child Health at MU. I devoted half of my time to research collaboration with Dr. Lindberg and the Medical Information Sciences Group. The position became the foundation of my ensuing academic career with a focus on informatics and domain knowledge in medical genetics.

MU's School of Medicine provided unending opportunities to expand my horizons as a faculty member. I spent 25 years at MU, and the time flew by.

When Dr. Lindberg became NLM's Director in 1984, he nominated me to be the Director of the Medical Information Sciences Group. The Dean of the School of Medicine appointed me to be the Director of the renamed Medical Informatics Group. Our work expanded to assist with teaching medical and nursing students how to search the literature to help with patient care.

We partnered with the J. Otto Lottes Health Sciences Library (Dean Schmidt MLS) to become a grant recipient from NLM for Integrated Advanced Information Management Systems (IAIMS), which involved strategic planning for the entire MU Health Sciences Center (HSC) schools and hospitals/clinics. I became Chief Information Officer of the MU-HSC and Associate Dean of the School of Medicine to achieve the goals of our strategic plans. Among many things, this involved replacing the majority of the systems in the hospitals and clinics to overcome the date problem associated with the new millennium $(\mathrm{Y} 2 \mathrm{~K})$ and simultaneously provided a foundation for an electronic medical record system. The latter experience might be likened to shoving a camel through the eye of a needle.

After MU-HSC successfully migrated its systems, I was ready to return to academic research and leave the $\mathrm{CIO}$ administrative role to a successor. As part of this transition, Dr. Lindberg suggested that I had earned a sabbatical and offered one to me at NLM.

\section{Sabbatical at NLM}

I arrived for my sabbatical at NLM in 2001 just as two momentous events occurred; the September 11, 2001 attack on the U.S. and the completion of the draft of the Human Genome Sequence. Incidentally, the 9/11 attack occurred during NLM's Board of Regents meeting. I will discuss both experiences and their impact on my work.

The events on $9 / 11$ provided memories many Americans vividly recall, and I witnessed the day through a unique vantage point at NLM's BOR. In addition to distinguished scientists and clinicians from a broad spectrum of the U.S.'s research and library communities, NLM's BOR consists of prominent members from the national agencies involved in informatics activities. In addition to the Directors of the two other U.S. national libraries (the Library of Congress and the National Agricultural Library), ex-officio members include the U.S. Surgeon General, the U.S. Medical Surgeons 
General of the Army, Navy, and Army Medical Command, the Undersecretary for the U.S. Veterans Health Administration, the President of the Uniformed Services University of the Health Sciences, and the Director for Biological Sciences of the National Science Foundation. I list all of them because the first speaker of the day was NIH's Director.

While NIH's Director was speaking, the first plane struck the World Trade Center, and the next hit the Pentagon. Before the third plane hit, all of the beepers in the room started calling these representatives to return to their duties post haste to save lives and the country. The U.S. President immediately decided to vacate the federal government, which included NIH. NIH's Director then asked NIH to close down all of their computers and evacuate.

Yet, Dr. Lindberg responded NLM's computational/information resources were designed to help the U.S. in times of disasters and emergencies, and NLM computers were not going to shut down. Dr. Lindberg knew NLM's information resources were instrumental in assisting with the chemicals released and created by the downed buildings and to search for critical literature to help care for the wounded. NLM's genomic resources also came into play to identify body parts found by matching DNA samples.

The day's events demonstrated how NLM was foundational to almost every aspect of medicine and public health and suggested the centrality of the Library's work. Along with NLM's staff, Dr. Lindberg had put the Library in an indispensable educational position in American medicine, health care, and society.

What a momentous time to start a sabbatical!

Moreover, 2001 marked the completion of the draft of the human genome sequence - the Human Genome Project's (HGP) goal. Although I arrived in August 2001 to stay for a year, I continued to work on my project for the next seven years.

Dr. Lindberg challenged me to develop a system that would help him explain the significance of the results of the HGP to legislators and the public. While he believed it was crucial for the federal funding for the HGP to continue unabated, the results and benefits were not clearly stated in terms of their relevance to human health. The challenge combined my expertise in genetics and bioinformatics with consumer health informatics.

The project became the Genetics Home Reference, a system that remains at NLM having recently merged into MedlinePlus, NLM's resource for consumer health information (https://medlineplus.gov/genetics/).

The original team included me, Alexa McCray, Ph.D., her staff, Sandra Davenport, M.D., and Rob Logan, Ph.D. We incorporated three design principles as we developed Genetics Home Reference that demonstrated their utility for the next 20 years.

Principle one was to make the site easy for the public to access with understandable content. Principle two was to interrelate and integrate existing resources extending from consumer health resources to clinical and scientific resources. Principle three was to create an informatics-based knowledge resource that would enhance the project's sustainability [1]. From the start, all content was edited for accuracy by medical geneticists who were members of the American College of Medical Genetics. The content also was revised to include lay language whenever possible. From its start in 2004, Genetics Home Reference was used heavily by the public, educators, librarians, and health care professionals, including medical geneticists. It was gratifying to create a resource for the world and to see it endure. 
Of course, several more opportunities were offered to me by Dr. Lindberg while I was on my sabbatical. I became involved in the NLM informatics course at the Marine Biological Institute in Woods Hole, MA., eventually becoming its Director. I became more involved with the International Medical Informatics Association (IMIA), and several European Union (EU) projects. I became more engaged with the American College of Medical Informatics (ACMI) and later was elected to be the President of ACMI.

But all good things like sabbaticals eventually must end. I returned to the MU as a professor in the newly created Department of Health Informatics and Administration. Shortly afterward, I was recruited to be chair of the Department of Medical Informatics at the University of Utah.

\section{University of Utah}

I spent the last ten years of my career with the joy of being chair of the world's first department of medical informatics, building on the legacy of Homer Warner M.D. and Reed Gardner Ph.D. Although there is much that I could share about this time, suffice it to say that many great projects were accomplished, and many people were involved. Dr. Lindberg continued to serve as my mentor as well as a colleague. He visited and gave talks on multiple occasions, including several days of vacation in the national parks. Photo 1 is a photo of Don and Mary Lindberg on the Great Salt Lake marina during one of those trips.

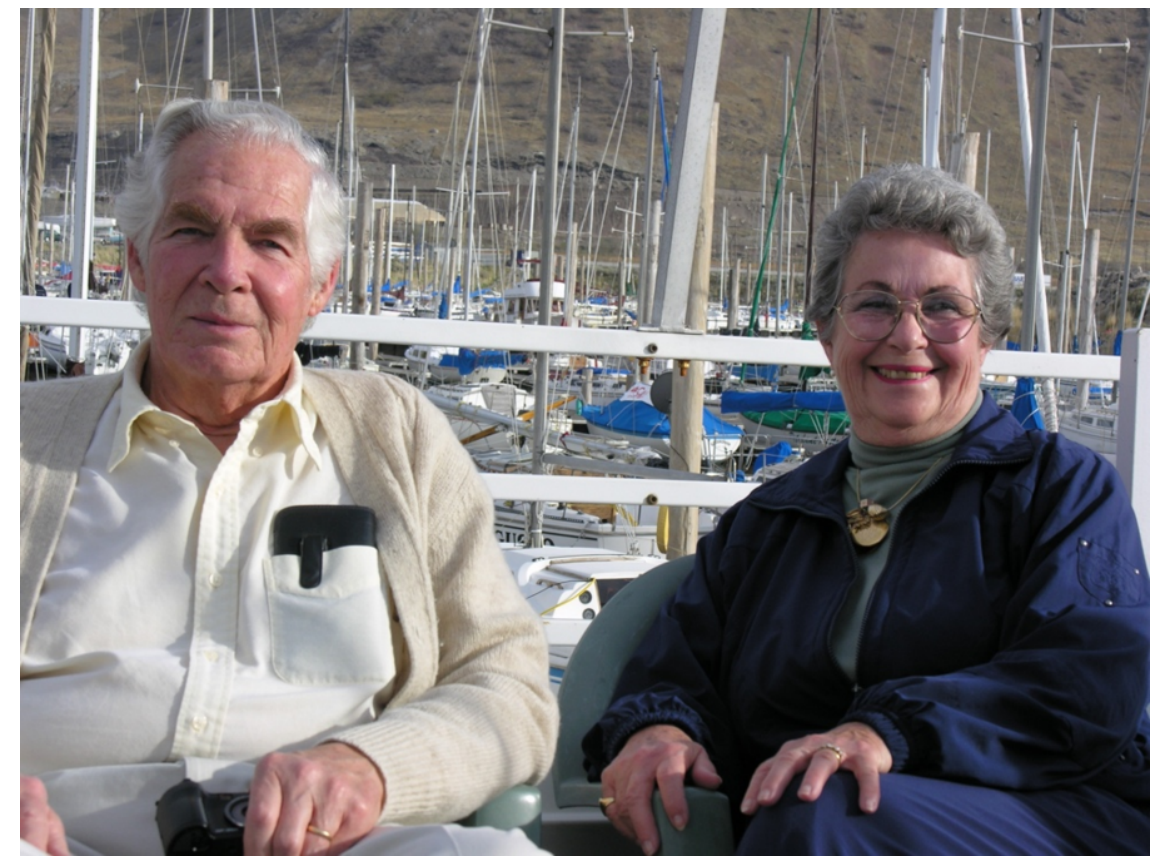

Photo 1. Don and Mary Lindberg on the Great Salt Lake marina. 


\section{Conclusion}

Dr. Lindberg changed my life and career trajectory by recruiting me to be a postdoctoral fellow at MU. He became my primary mentor as I progressed in the field that became known as Biomedical Informatics. With his guidance, I progressed from being a complete novice to an internationally recognized biomedical informatics professional. My ultimate accomplishment was being appointed a NLM Board of Regents member, eventually serving as its chair. I also was selected to be NLM's representative on the NIH Council of Councils, which helped advise NIH's Director, Francis Collins M.D., Ph.D. Dr. Lindberg was always available, insightful, interested, listened, gave his best advice, and followed up. He was a remarkable mentor, and my gratitude persists.

\section{Reference}

[1] Mitchell JA, Fun J, McCray AT. Design of the Genetics Home Reference: a new NLM consumer health resource. J Am Med Inform Assoc. 2004;6:439-447. 